\title{
Gas and dust exposure in underground construction is associated with signs of airway inflammation
}

\author{
B. Ulvestad*,\#, M.B. Lund", B. Bakke , P.G. Djupesland ${ }^{+}$, J. Kongerud", J. Boe
}

Gas and dust exposure in underground construction is associated with signs of airway inflammation. B. Ulvestad, M.B. Lund, B. Bakke, P.G. Djupesland, J. Kongerud, J. Boe. (C) ERS Journals Ltd 2001.

ABSTRACT: Exposure to gases and dust may induce airway inflammation. It was hypothesized that heavy construction workers who had been exposed to dust and gases in underground construction work for $1 \mathrm{yr}$, would have early signs of upper and lower airway inflammation, as compared to outdoor workers.

A study group comprising 29 nonsmoking underground concrete workers (mean \pm SD age $44 \pm 12 \mathrm{yrs}$ ), and a reference group of 26 outdoor concrete workers ( $39 \pm 12 \mathrm{yrs})$ were examined by acoustic rhinometry, nasal and exhaled nitric oxide spirometry and a questionnaire on respiratory symptoms. Exposure measurements were carried out.

The underground workers had higher exposure to total and respirable dust, $\alpha$-quartz and nitrogen dioxide than the references $(p<0.001)$. The occurrence of respiratory symptoms was higher in the underground workers than in the references $(p<0.05)$. Exhaled nitric oxide (NO) (geometric mean \pm SEM) was higher in the underground workers than in the references $(8.4 \pm 1.09$ versus $5.6 \pm 1.07$ parts per billion (ppb), $p=0.001$, whereas spirometric values were comparable. The underground workers had smaller nasal cross-sectional area and volume than the references, and more pronounced increases after decongestion $(p<0.001)$.

To conclude the exposure in underground construction may cause nasal mucosal swelling and increased levels of exhaled nitric oxide, indicating signs of upper and lower airway inflammation.

Eur Respir J 2001; 17: 416-421.
*Selmer ASA, Oslo, Norway, ${ }^{\#}$ Dept of Thoracic Medicine, National Hospital, University of Oslo, Norway, "National Institute of Occupational Health, Oslo, Norway and ${ }^{+}$Dept of Otorhinolaryngology, Ullevål University Hospital, Oslo, Norway.

Correspondence: B. Ulvestad, Selmer ASA, P.b. 1175 Sentrum, N-0107 Oslo, Norway

Fax: 4722208830

Keywords: Acoustic rhinometry airway inflammation exhaled nitric oxide

dust and gas exposure

Received: July 32000

Accepted after revision September 14 2000

The work was financially supported by the Working Environment Fund of the Confederation of Norwegian Business and Industry.
Air pollution is a health problem in heavy construction industry, particularly in underground work. Dust, originating from work-operations like drilling, blasting and grinding, becomes airborne, and inhalation of particles may induce accelerated lung function decline [1]. In a study of males with occupational exposure to quartz, the duration of exposure was shown to be an independent predictor of spirometric airflow limitation [2]. Underground construction workers are also exposed to particles and nitrogen dioxide $\left(\mathrm{NO}_{2}\right)$ from diesel exhaust [1]. In healthy subjects, an inflammatory response has been observed in bronchoalveolar lavage fluid, after exposure to diesel emissions in a provocation chamber [3].

Endogenous nitric oxide (NO) is thought to play an important role in the pathophysiology of airway diseases [4]. Increased concentrations of NO have been detected in exhaled air of patients with asthma and other inflammatory airway disorders [5], suggesting that expired NO may serve as a marker of airway inflammation. In occupational settings, exhaled NO has been used to assess the irritant effect of ozone exposure [6], and as a possible marker of asthma in aluminium potroom workers [7]. Increased levels of nasal NO have been found in patients with rhinitis, and have been suggested as a marker of nasal inflammation [8]. In recent years, acoustic rhinometry has gained acceptance as an objective, noninvasive method for examining upper airway patency [9]. As they may provide simple, noninvasive means for detecting airway inflammation, acoustic rhinometry and measurements of nasal and exhaled NO may possibly become useful tools in occupational medicine.

Occupationally induced airways obstruction has been demonstrated in workers exposed to cotton dust, in coal workers and in grain workers [10]. Little is described about exposure and airway responses in workers in heavy construction industry, an industry with multifactorial exposures [1]. It was hypothesized that workers who had been exposed to tunnelling pollutants for $1 \mathrm{yr}$, would have early signs of upper and lower airway inflammation, as compared to reference subjects who had performed the same job tasks outdoors. In order to detect early inflammatory changes of the upper and lower airways, modern, sensitive, noninvasive methods were employed. Exposure measurements were carried out to demonstrate the environmental differences between the two groups.

\section{Material and methods}

\section{Tunnel site selection and characteristics}

A tunnel site in Oslo, Norway, was selected. The excavation work was finished, and the study was 
performed during on-going concrete work. The volume of the excavated tunnel was $124,000 \mathrm{~m}^{3}$. It had a local one-way ventilation system and the airflow into the tunnel area was $\sim 1800 \mathrm{~m}^{3} \cdot \mathrm{min}^{-1}$. The machinery operated inside the tunnel was diesel powered.

\section{Exposure}

Exposure to dust and gases was determined by means of personal sampling. Each person measured two or more agents for one or two days. Total dust was collected on acryl copolymer membrane filters (Versapore 800 ) with pore size $0.8 \mu \mathrm{m}$ in $25 \mathrm{~mm}$ aerosol filter cassettes (Gelman Sciences, Ann Arbor, USA) with a sampling flow rate of $2.0 \mathrm{~L} \cdot \mathrm{min}^{-1}$. Respirable dust was collected on $37 \mathrm{~mm}$ cellulose acetate filters with pore size $0.8 \mu \mathrm{m}$ by using a cyclone separator (Casella T13026/2, London, UK) with a sampling flow rate of $2.2 \mathrm{~L} \cdot \mathrm{min}^{-1}$. The sampling time varied $5-7 \mathrm{~h}$. The particle mass was analysed with a microbalance (Sartorius AG, Goettingen, Germany). The determination of $\alpha$-quartz in the respirable fraction was analysed by X-ray diffraction [11]. Gas concentrations of $\mathrm{NO}_{2}$ were measured by direct reading instruments, electrochemical sensors with data-logging facility built into the instrument (Neotox-xl personal single-gas monitor, Neotronics Limited, Takeley, UK). A sampling rate of one reading every second minute was selected. The sensors were calibrated every third month with certified calibration gases.

\section{Study populations}

The study group was based on all male concrete workers $(n=59)$, who had been performing finishingwork for a period of $1 \mathrm{yr}$ after the excavation of the tunnel, but otherwise had no previous tunnel work experience. From this group, only nonsmokers $(n=29)$ were invited to participate in the study. Reference subjects were recruited from three outdoor construction sites located in the vicinity of the tunnel site. All nonsmoking subjects $(n=26)$ from the 55 outdoor concrete workers who had never worked in tunnels, were invited to the study. None of the subjects reported physician-diagnosed asthma, which was a criterion of exclusion from the study. All participants had to be free from respiratory infections for three weeks prior to testing. Nonsmokers were defined as never-smokers and former smokers (smoking cessation > 12 months). Smokers were excluded in order to avoid the concomitant effects of tobacco-smoke pollutants on the respiratory system and because cigarette smokers are known to have decreased NO levels [12]. The underground workers and the reference subjects performed the same job tasks, and had the same work schedule (10 h shifts with two breaks of $30 \mathrm{~min}$ each). The study was carried out between September and November 1998. The attendance rate was $100 \%$ for both the index group and the reference group. All subjects were tested during the working day at a hospital located $10 \mathrm{~min}$ from the work sites. The study was approved by the
Data Inspectorate and the Regional Medical Ethics Board.

\section{Questionnaire}

A self-administered questionnaire applied in earlier Norwegian investigations [13, 14] and validated in a previous study [15], was used to assess the presence of airways symptoms. Questions included the occurrence of work-related sore throat, nasal congestion, cough with phlegm, chest tightness and wheeze. The questionnaire also asked about former smoking.

\section{Immunoglobulin E measurements}

Screening for atopic allergy was done with Phadiatop (Pharmacia Diagnostics AB, Uppsala, Sweden), a multiple radio allergo sorbent test (RAST) of immunoglobulin (Ig)E against nine common respiratory allergens (birch, timothy, mugwort, cladosporium herbarum, alternaria tenuis, dermatophagoides pteronyssinus, cat dander, dog epithelium, horse dander) [16]. Total IgE was measured by the UniCap method (Pharmacia Diagnostics AB, Uppsala, Sweden).

\section{Acoustic rhinometry}

Acoustic rhinometry was performed with the Rhin2100 (Rhino Metrics AS, Denmark) with the subject in the seated position and stabilization of the head, but without instrument fixation [17]. Briefly, in this method acoustic signals generated in a tubular probe wave tube are conducted via a nasal adapter to the nasal cavity. The incident signal and its reflections from the nasal cavity are detected by a microphone within the sound wave tube. Resulting electrical signals are processed by analysing software to provide a graphic display of cross-sectional area-distance relationships and numeric descriptions of minimum crosssectional areas and volumes between selected points in the nasal cavity. The following variables were recorded: the total (sum of unilateral) minimum cross-sectional areas (TMCA1, TMCA2) and volumes (TVOL1, TVOL2), measured at 1) the anterior $22 \mathrm{~mm}$ of the nasal cavity and 2) $22-52 \mathrm{~mm}$ from the nostril. Three independent traces for each nasal airway were recorded, and the mean values computed. Coefficients of variation $(\mathrm{CV})$ were also recorded. TMCA $2 \leqslant 0.9 \mathrm{~cm}^{2}$ was considered a threshold value, predicative of subjective feeling of nasal obstruction [18]. Measurements were performed before, and 15 minutes after, standardized application of a nasal spray containing xyclometazolin. The degree of mucosal swelling was estimated indirectly via the decongestive effect [9].

\section{Nitric oxide measurements}

NO was measured by a chemiluminescence analyser (LR 2000, Logan Research, Rochester, UK) adapted for on-line recording of NO concentration, as 
previously described [7]. The sampling rate of the analyser was set to $250 \mathrm{~mL} \cdot \mathrm{min}^{-1}$ for all measurements. The analyser was calibrated daily using certified NO mixtures (100 parts per billion (ppb)) in nitrogen (BOC Special Gases, Surrey Research Park, Guildford, UK). Ambient NO was recorded daily. Exhaled and nasal NO measurements were performed in accordance with recommendations outlined in the European Respiratory Society's Task Force Report [19]. Measurements of exhaled NO were made by slow exhalation $(20-30 \mathrm{~s})$ from total lung capacity through a Teflon mouthpiece, against a mild resistance (target mouth pressure of $4-5 \mathrm{cmH}_{2} \mathrm{O}$ ) to avoid nasal NO contamination. Endexpiratory $\mathrm{NO}$ values were measured at the plateau level of the last part of the exhalation curve. Nasal NO was measured with a Teflon tube inserted into one of the nares, while the subject held breath, and the value of the last plateau part of the trace recorded. For both exhaled and nasal measurements, three technically acceptable measurements were obtained, and the mean of the two closest measurements was reported.

\section{Spirometric measurements}

Spirometry was performed using a pneumotachograph (Vitalograph, Birmingham, UK) which was calibrated daily by a $1 \mathrm{~L}$ syringe. The measurements were performed in accordance with the guidelines recommended by the American Thoracic Society [20]. Recorded variables were forced vital capacity (FVC), forced expiratory volume in one second (FEV1), and $\mathrm{FEV} 1 / \mathrm{FVC} \times 100(\mathrm{FEV} 1 \%)$. The lung function variables were expressed in absolute values and as percentage of predicted, using the reference values of the European Coal and Steel Community (ECSC) [21].

\section{Statistical methods}

The relationship between respiratory symptoms and the covariates occupational group and age was investigated by means of logistic regression. The covariate years employed in the same job was not included in the model due to high correlation $(>0.8)$ with the covariate age. Atopy and former smoking were controlled for, but did not have any influence on the models. The relationship between acoustic rhinometry data prior to nasal decongestion and the covariates occupational group and age were investigated by means of analysis of variance (ANOVA). Since age had no influence on the statistical model, unadjusted data are presented and summarized for each occupational group. Changes in acoustic rhinometry after nasal decongestion were evaluated using ANOVA with occupational group and acoustic rhinometry data prior to nasal decongestion as covariates in the model. Exhaled and nasal NO data were analysed using the same ANOVA model as for the acoustic rhinometry data prior to nasal decongestion. Age had no influence on the model and unadjusted data are presented. Values for exhaled NO were log transformed. The relationship between lung function data and the covariates occupational group and age were investigated by means of ANOVA. The exposure data were best described by log-normal distributions and were log-transformed before statistical analyses.

\section{Results}

\section{Exposure characterization}

Table 1 shows the geometric mean exposure levels by occupational group. The underground workers had significantly higher exposure to total- and respirable dust than the outdoor workers. They were also exposed to significantly higher levels of $\alpha$-quartz and $\mathrm{NO}_{2}$. The highest $8-\mathrm{h}$ time-weighted averages were: total dust $=19.4 \mathrm{mg} \cdot \mathrm{m}^{-3}$, respirable dust $=4.4 \mathrm{mg} \cdot \mathrm{m}^{-3}$ and $\alpha$-quartz $=0.16 \mathrm{mg} \cdot \mathrm{m}^{-3}$. The underground workers were periodically exposed to high concentrations of $\mathrm{NO}_{2}$ (peak value $7.4 \mathrm{ppm}$ (ceiling value $2 \mathrm{ppm}$, Norway 1998)). $\mathrm{NO}_{2}$ concentrations outdoors were not detectable with the method used.

Table 1. - Personal exposure to total dust, respirable dust, $\alpha$-quartz and nitrogen dioxide during underground or outdoor concrete work

\begin{tabular}{|c|c|c|c|c|c|c|c|c|}
\hline & & dust $^{\#} \mathrm{mg} \cdot \mathrm{m}^{3}$ & Resp & dust $^{\top} \mathrm{mg} \cdot \mathrm{m}^{3}$ & & $\operatorname{artz}^{+} \mathrm{mg} \cdot \mathrm{m}^{3}$ & Nit & gen dioxide ${ }^{\S}$ ppm \\
\hline & $\mathrm{n}$ & & $\mathrm{n}$ & & $\mathrm{n}$ & & $\mathrm{n}$ & \\
\hline $\begin{array}{l}\text { Underground } \\
\text { Outdoor }\end{array}$ & $\begin{array}{l}27 \\
35\end{array}$ & $\begin{array}{c}5.40 \pm 1.42^{f} \\
1.0 \pm 1.78\end{array}$ & $\begin{array}{l}30 \\
40\end{array}$ & $\begin{array}{l}1.61 \pm 1.43^{f} \\
0.21 \pm 1.69\end{array}$ & $\begin{array}{l}30 \\
40\end{array}$ & $\begin{array}{l}0.087 \pm 1.61^{f} \\
0.003 \pm 1.82\end{array}$ & $\begin{array}{l}3 \\
5\end{array}$ & $0.90 \pm 1.81^{f}$ \\
\hline $\begin{array}{l}\text { Data present } \\
{ }^{+}: \mathrm{HS}=0.1 \mathrm{~m}\end{array}$ & & $\begin{array}{l}\text { metric mea } \\
=2.0 \text { parts } \mathrm{F}\end{array}$ & $\begin{array}{l}\text { D. } \\
\text { llion }\end{array}$ & $\begin{array}{l}\text { wegian hygi } \\
\text { g value); } * * * *\end{array}$ & 0.08 & $\begin{array}{c}\text { ards }(\mathrm{HS})=1 \\
\text { nd: not detec }\end{array}$ & $\cdot \mathrm{m}^{3}$ & ๑: $\mathrm{HS}=5.0 \mathrm{mg} \cdot \mathrm{m}^{3}$; \\
\hline Airway sympt & & & & Undergroun & rker & & & Outdoor workers \\
\hline Congested nos & & & & $22(76$ & & & & $11(42)$ \\
\hline Sore throat & & & & $19(65$ & & & & $6(23)$ \\
\hline Cough with pl & & & & $11(38$ & & & & $0(0)$ \\
\hline Chest tightnes & nd & & & $11(38$ & & & & $0(0)$ \\
\hline
\end{tabular}

Data presented as $\mathrm{n}(\%)$. * denotes $\mathrm{p}<0.05$ underground/outdoor adjusted for age in a logistic regression model. 
Table 3. - Acoustic rhinometry data in 29 underground workers and 26 outdoor workers

\begin{tabular}{|c|c|c|c|c|}
\hline & \multicolumn{2}{|c|}{ Prior to nasal decongestion } & \multicolumn{2}{|c|}{ Change after nasal decongestion } \\
\hline & Underground & Outdoor & Underground & Outdoor \\
\hline TMCA1 $\mathrm{cm}^{2}$ & $0.94(0.04) *$ & $1.12(0.06)$ & $0.15(0.05)$ & $0.02(0.05)$ \\
\hline TVOL $1 \mathrm{~cm}^{3}$ & $3.69(0.13)$ & $3.83(0.17)$ & $0.17(0.10)$ & $-0.08(0.11)$ \\
\hline TMCA2 $\mathrm{cm}^{2}$ & $0.97(0.05)^{* * *}$ & $1.14(0.07)$ & $0.35(0.05)^{*}$ & $0.11(0.04)$ \\
\hline TVOL $2 \mathrm{~cm}^{3}$ & $6.62(0.29)^{* * *}$ & $7.57(0.41)$ & $4.04(0.27)^{*}$ & $2.15(0.28)$ \\
\hline
\end{tabular}

Data presented as mean \pm SEM. TMCA1: total minimum cross-sectional area in the anterior $22 \mathrm{~mm}$ of the nasal cavity; TVOL1: total volume of the anterior $22 \mathrm{~mm}$ of the nasal cavity; TMCA2: total minimum cross-sectional area between 22 and $52 \mathrm{~mm}$ from the nostril; TVOL2: total volume of the area between 22 and $52 \mathrm{~mm}$ from the nostril; ${ }^{*}: \mathrm{p}<0.05$ underground versus outdoor; $* * *: \mathrm{p}<0.001$ underground versus outdoor.

\section{Clinical findings and symptoms}

The underground workers were somewhat older than the reference subjects (mean $\pm \mathrm{SD}$ age $44 \pm 12$ versus $39 \pm 12 \mathrm{yrs}$ ). The two groups were comparable with respect to years of employment $(20 \pm 9$ versus $17 \pm 12 \mathrm{yrs})$, height $(178 \pm 6$ versus $178 \pm 6 \mathrm{~cm})$, atopy $(\mathrm{n}=5$ versus $\mathrm{n}=6)$ and former smoking $(\mathrm{n}=5$ versus $\mathrm{n}=6$ ). Work-related upper airways symptoms were more pronounced in the underground workers (table 2). They also reported higher occurrence of symptoms from the lower airways. Both productive cough and chest tightness and wheeze occurred more frequently in the underground workers than in the reference subjects (table 2 ).

\section{Acoustic rhinometry}

Prior to decongestion, the underground workers had significantly lower absolute values of TVOL2, TMCA1 and TMCA 2 than the outdoor workers (table 3 ). The increases in TMCA2 and TVOL2 after nasal decongestion were significantly more pronounced in the underground workers (table 3). There was no significant difference in TVOL1 between the two groups. TMCA2 $=0.9 \mathrm{~cm}^{2}$ was correlated to a subjective feeling of nasal congestion (Pearson correlation $=0.4$, $\mathrm{p}=0.001)$. The repeatability of the measurements was high (mean $\mathrm{CV}=3 \%$ for TMCA2 and $2 \%$ for TVOL 2 ).

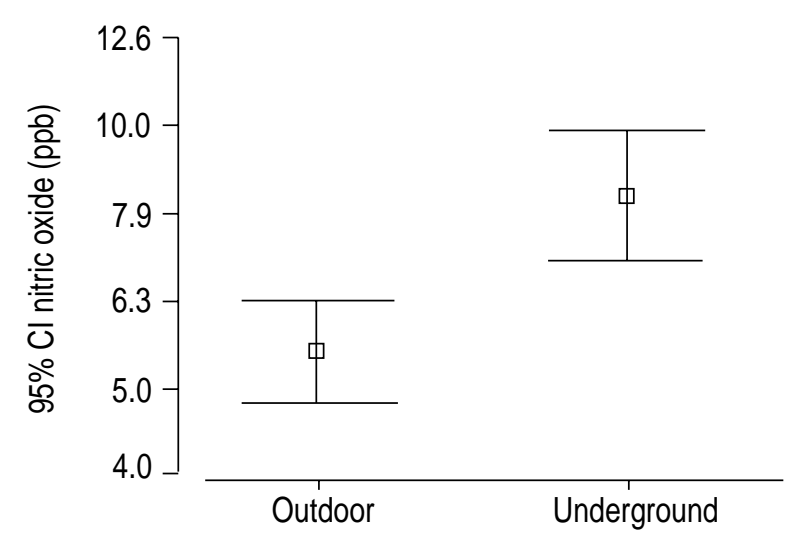

Fig. 1. - Exhaled nitric oxide (geometric mean \pm SEM) in 29 underground workers and 26 outdoor workers. ppb: parts per billion; 95\% CI: 95\% confidence interval.

\section{Nasal and exhaled NO}

Nasal NO levels did not differ between the underground workers and the outdoor workers (arithmetic mean \pm SEM) $882 \pm 42$ versus $827 \pm 54 \mathrm{ppb}$. Workers reporting nasal congestion had significantly higher nasal NO levels than workers without the complaint $(910 \pm 46$ versus $779 \pm 45 \mathrm{ppb}, \mathrm{p}=0.04)$.

The underground workers had significantly higher levels of exhaled NO than the outdoor workers $(8.4 \pm 1.1$ versus $5.6 \pm 1.1 \mathrm{ppb}, \mathrm{p}=0.003)$ (fig. 1$)$. The exhaled NO levels in underground workers complaining of having chest tightness and wheeze $(n=11)$ were significantly higher than in workers without the complaint $(9.6 \pm 1.2$ versus $6.3 \pm 1.1 \mathrm{ppb}, \mathrm{p}=0.004)$.

\section{Spirometry}

The underground workers did not differ significantly from the reference subjects with respect to spirometric values (FVC $102 \pm 2$ versus $103 \pm 5 \%$ pred, and FEV1 $94 \pm 2$ versus $100 \pm 3 \%$ pred). Only three of the 11 underground workers who reported chest tightness and wheezing had FEV1/FVC ratio $<0.7$.

\section{Discussion}

The main finding of this study was that subjects who had worked in underground construction for $1 \mathrm{yr}$ had significantly increased occurrence of upper and lower respiratory symptoms, nasal mucosal swelling and exhaled NO-levels, compared to subjects who had performed the same job tasks outdoors. The two study groups were otherwise comparable with respect to atopy, former smoking habits and years of employment in heavy construction industry. Since the underground workers were somewhat older than the reference subjects (mean age 44 versus 39 yrs), age was controlled for in all relevant statistical analyses, but had no influence on the models.

Compared to the outdoor workers, the underground workers had significantly higher exposure to $\mathrm{NO}_{2}$ and dust, most likely caused by exhaust from diesel powered machinery operated inside the tunnel and dust from sandblasting (not silica-containing) performed in the vicinity of on-going concrete work. The method used for collecting total dust (pore size $0.8 \mu \mathrm{m}$ in $25 \mathrm{~mm}$ aerosol filter cassettes) is known to under-estimate 
particles $>30 \mu \mathrm{m}$ [22], and will probably have underestimated the levels of larger particles in the tunnel environment. Due to high humidity caused by watersupported drilling, use of cassettes with larger pore size in tunnels may be less adequate. Diesel engines, in addition to generating large amounts of $\mathrm{NO}_{2}$, also produce small particles (diameter $0.002-0.02 \mu \mathrm{m}$ ) [23]. Such particles may stay airborne for long periods of time [23-25] and deposit in greater numbers and more peripherally in the airways than larger particles.

The nose is the preferred and natural entry to the respiratory tract. It filters the inspired air for large particles and protects the lower airways. In a tunnel work environment, in which large particles are present, it is likely that pathological airway changes first will be manifest in the nose. The underground workers reported nearly two-fold higher occurrence of nasal congestion than the outdoor workers, and this finding was supported by objective rhinometric measurements. Prior to decongestion, the underground workers had significantly smaller nasal cross-sectional areas and volumes than the outdoor workers, and the effect of decongestion was significantly more pronounced. This means that nasal mucosal swelling was significantly larger in the underground workers than in the outdoor workers. Also, mean nasal cross-sectional area in the underground workers was close to the threshold value considered predicative of feeling nasal obstruction [18]. The high repeatability of rhinometric measurements indicates that mechanical errors such as distortion of the nostril and sound leakage were avoided.

Significant differences in nasal NO between the two groups were not found. One explanation would be that the method used for nasal NO measurements was based on low airflow $\left(250 \mathrm{~mL} \cdot \mathrm{min}^{-1}\right)$, in accordance with recommendations at that time. However, recent studies have shown that aerodynamic factors may influence nasal NO output at low airflows [26], and the optimal flow-range in adults is now thought to be $3.2-5.2 \mathrm{~L} \cdot \mathrm{min}^{-1}$ [27]. Higher and more physiological aspiration flows might have allowed detection of true group differences in nasal NO-output which remained undetected at low aspiration flows [27].

Levels of exhaled NO and occurrence of lower respiratory symptoms were significantly higher in the underground workers than in the outdoor workers. Although the measured NO-levels were not quite as high as those found in aluminium potroom workers [7], they were comparable to those reported after ozone exposure [6], and higher than those observed in exsmokers with chronic obstructive pulmonary disease (COPD) [28]. Whether the observed difference in exhaled NO between underground workers and reference subjects is biologically important, as distinct from statistically significant, cannot be categorically answered. However, two other studies, both performed with the same type of NO analyser and methodology as applied in the presented study, may suggest biological importance. HENRIKSEN et al. [29] reported differences in exhaled NO between respectively, subjects with allergic rhinitis and healthy, nonatopic controls, and atopic subjects with and without bronchial hyperresponsiveness to methacholine, comparable to that observed in the present study [29]. MAZIAK et al. [28] found differences in exhaled NO between smokers with and without COPD respectively, and COPD patients with and without inhaled steroids, of a similar magnitude.

The elevated levels of exhaled NO in underground workers may reflect early signs of airway inflammation caused by pollutants in the work atmosphere. Shortterm exposure to diesel exhaust has been shown to produce inflammatory responses in the airways of healthy humans [30]. In a previous study an increased prevalence of COPD and accelerated annual decline in FEV1 was observed in tunnel workers, compared to outdoor heavy construction workers [1]. The subjects who reported lower respiratory symptoms had significantly higher NO-levels than those who reported no symptoms. This supports the hypothesis that their symptoms do in fact reflect airway inflammation as in COPD. Since smokers were excluded from the study, the most common cause of COPD was ruled out. No subject in the reference group working outdoors reported lower respiratory airway symptoms. To strengthen the observation that the increased levels of exhaled NO observed in the exposed subjects did in fact reflect airway inflammation, would have required comparison with other markers of airway inflammation (i.e. induced sputum, bronchoalveolar lavage or bronchial biopsies). Positive correlation with those markers would have contributed to strengthen the relevance of the present findings, but in the present occupational setting such complicated test procedures could not be performed.

No significant differences in spirometry were found between the underground workers and the references. The reasons may be that the number of subjects in each group was small and the period of exposure short (1 yr). Significant spirometric differences between the workers who reported lower respiratory symptoms and those who did not were not observed either. This may indicate that the symptomatic workers had not yet developed manifest COPD, but a mild, subclinical condition. Also, spirometry may be too crude to detect early signs of airway inflammation in a cross-sectional study. Only when inflammation has resulted in sufficient morphological changes to produce manifest obstruction, will FEV1 be reduced.

The high occurrence of upper and lower respiratory symptoms reported by the underground workers may partly reflect their awareness of a possible occupational health risk. However, although response bias may explain over-reporting of symptoms, it would hardly affect data obtained by objective methods, such as acoustic rhinometry and measurement of NO. A healthy worker selection bias may also have influenced the present results. Sensitive workers may have asked to be relocated when assigned to work underground. Hence a selection bias would have implied a selection of healthy workers to the tunnel site. This, in turn, would imply as bias towards a potentially higher occurrence of respiratory disorders in the control subjects. The fact that the authors found increased occurrence of respiratory symptoms and nasal congestion and higher levels of exhaled NO in the presumably "healthiest" group, should therefore strengthen the significance of these observations. 
To conclude, the exposure to pollutants in underground construction work is associated with increased occurrence of airway symptoms, nasal mucosal swelling and elevated levels of nitric oxide in exhaled air. These findings may suggest early signs of inflammation affecting both upper and lower airways.

Acknowledgements. The authors wish to thank P. Fuglerud, (Parexel Medstat, Norway) for statistical assistance.

\section{References}

1. Ulvestad B, Bakke B, Melbostad E, Fuglerud P, Kongerud J, Lund MB. Increased risk of obstructive pulmonary disease in tunnel workers. Thorax 2000; 55: 277-282.

2. Humerfelt S, Eide GE, Gulsvik A. Association of years of occupational quartz exposure with spirometric airflow limitation in Norwegian men aged 30-46 years. Thorax 1998; 53: 649-655.

3. Rudell B, Blomberg A, Helleday $\mathrm{R}$, et al. Bronchoalveolar inflammation after exposure to diesel exhaust: comparison between unfiltered and particle trap filtered exhaust. Occup Environ Med 1999; 56: $527-534$.

4. Borland C, Cox Y, Higenbottam T. Measurement of exhaled nitric oxide in man. Thorax 1993; 48: 1160 1162.

5. Von Essen SG, Scheppers LA, Robbins RA, Donham KJ. Respiratory tract inflammation in swine confinement workers studied using induced sputum and exhaled nitric oxide. Clin Toxicol 1998; 36: $557-$ 565.

6. Olin AC, Ljungkvist G, Bake B, Hageberg S, Henriksson L, Torén K. Exhaled nitric oxide among pulpmill workers reporting gassing incidents involving ozone and chlorine dioxide. Eur Respir J 1999; 14: $828-831$

7. Lund MB, Øksne PI, Hamre R, Kongerud J. Increased nitric oxide in exhaled air: an early marker of asthma in non-smoking aluminium potroom workers. Occup Environ Med 2000; 57: 274-278.

8. Olin AC, Hellgren J, Karlsson G, Ljungkvist G, Nolkrantz K, Torén K. Nasal nitric oxide and its relationship to nasal symptoms, smoking and nasal nitrate. Rhinol 1998; 36: 117-121.

9. Taverner D, Bickford L, Shaib S, Tonkin A. Evaluation of the dose-response relationship for intra-nasal oxymetazoline hydrochlorine in normal adults. Eur J Clin Pharmacol 1999; 55: 509-513.

10. Garshick E, Schenker MB, Dosman JA. Occupationally induced airways obstruction. Med Clin North Am 1996; 80: 851-878.

11. US Department of Health Human Services. NIOSH manual of analytical methods. Silica, crystalline, by XRD Method 7500. DHHS (NIOSH) 1998; 4: 1-8.

12. Kharitonov SA, Robbins RA, Yates D, Keating V, Barnes PJ. Acute and chronic effects of cigarette smoking on exhaled nitric oxide. Am J Respir Crit Care Med 1995; 152: 609-612.
13. Kongerud J, Groennesby JK, Magnus P. Respiratory symptoms and lung function of aluminium potroom workers. Scand J Work Environ Health 1990; 16: 270 277.

14. Melbostad E, Eduard W, Magnus P. Chronic bronchitis in farmers. Scand J Work Environ Health 1997; 23: $271-280$.

15. Kongerud J, Vale JR, Aalen OO. Questionnaire reliability and validity for aluminium potroom workers. Scand J Work Environ Health 1989; 15: $364-370$.

16. Eriksson NE. Allergy screening with Phadiatop and CAP Phadiatop in combination with a questionnaire in adults with asthma and rhinitis. Allergy 1990; 45: $285-292$.

17. Hilberg O, Jackson AC, Swift DL, Pedersen OF. Acoustic rhinometry: Evaluation of nasal cavity geometry by acoustic reflection. J Appl Physiol 1989; 66: $295-303$.

18. Grymer LH, Hilberg O, Pedersen OF. Prediction of nasal obstruction based on clinical examination and acoustic rhinometry. Rhinol 1997; 35: 53-57.

19. Kharitonov S, Alving K, Barnes PJ. Exhaled and nasal nitric oxide measurements: recommendations. Eur Respir J 1997; 10: 1683-1687.

20. American Thoracic Society. Standardization of spirometry-1987 update. Am Rev Respir Dis 1987; 136: $1285-1298$.

21. Quanjar PH, Tammeling GJ, Cotes JE. Standardized lung function testing. Eur Respir $J$ 1993; 10: $1683-$ 1693.

22. Pergamon JHV. Aerosol science for industrial hygienists. Elsevier Science LTD, Oxford, UK 1995.

23. Sawyer RF, Johnson JH. 1995. Diesel emissions and control technology. In: Diesel Exhaust-A critical analysis of emissions, exposure and health effects. (A special report on the Institute's Diesel Working group), health Effects Institute, Cambridge; MA. pp. $68-81$.

24. Vistal JJ. Health effects of diesel particulate emissions. Bull NY Acad Med 1980; 56: 914-934.

25. Quality of urban air review group. 1996. Sources and emissions of primary particulate matter in the United Kingdom Department of Environment, Third Report, pp. 37-55.

26. Djupesland PG, Chatkin JM, Qian W, et al. Aerodynamic influences on nasal nitric oxide output measurements. Acta Otolaryngol 1999; 119: 479-485.

27. Qian W, Djupesland PG, Chatkin JM, et al. Aspiration flow optimized for nasal nitric oxide measurement. Rhinol 1999; 37: 61-65.

28. Maziak W, Loukides S, Culpitt S, Sullivan P, Kharitonov SA, Barnes PJ. Exhaled nitric oxide in chronic obstructive pulmonary disease. Am J Respir Crit Care Med 1998; 157: 998 - 1002.

29. Henriksen AH, Sue-Chu M, Lingaas-Holmen T, Langhammer S, Bjermer L. Exhaled and nasal NO levels in allergic rhinitis: relation to sensitization, pollen season and bronchial hyperresponsiveness. Eur Respir J 1999; 13: 301-306.

30. Blomberg A. Inflammatory and antioxidant responses in the airways to oxidative and particulate air pollution. PhD thesis Umeå: University of Umeå. 